\title{
Levels of Educational Goals Used by Teachers in the Light of Some Variables in Amman Directorate of Education in Jordan
}

\author{
Rafe Msaedeh $^{1}$ \\ ${ }^{1}$ Irbid National University, Irbid, Jordan \\ Correspondence: Rafe Msaedeh, Irbid National University, Irbid, Jordan.
}

Received: August 8, 2018

doi:10.5539/ies.v12n1p103
Accepted: September 11, $2018 \quad$ Online Published: December 28, 2018

URL: https://doi.org/10.5539/ies.v12n1p103

\begin{abstract}
The aim of the study was to determine the levels of educational goals used by teachers in their daily preparation notes in Amman directorate of education, and whether their use varied according to the educational stage they are involving in, or years of experience or gender. The sample of the study consisted of (126) teachers teaching different educational stages, 62 Males and 64 females. The results of the $x^{2}$ test showed that teachers' use of emotional goals was very little compared to their use of cognitive goals, and their use of psychological goals was little compared to their use of the most commonly used cognitive goals.
\end{abstract}

Keywords: educational goals, teachers of Amman directorate of education, Jordan

\section{Introduction}

Educational objectives are the cornerstone of planning. It is the means of the teacher to achieve what he wants, to give his students the skills and ideas to form the human personality in all its aspects, mental, spiritual, psychological, and social; to be a human being contributes in building his homeland and nation. Hence, educational goals are important in the fields of education which are important input in the evaluation of educational learning process. They organize and reduce efforts to reach the desired goal. The teacher must formulate them properly after studying and reading in depth for what he wants to know taking into consideration that each goal must be preceded by conceptual readiness and end with a phased assessment.

Educational objectives are defined as the product of a particular educational situation which means the specific skills to be developed through the teaching of a specific study experience or specific content of the curriculum (Stoyanova \& Yovkov, 2016). As well as to teach these principles, values and beliefs through education which means organized and intended knowledge, each Muslim individual is required to achieve both. Moreover, the educational goals in the perspective of Islamic education are focused on the goals of his relative, such as the welfare of the individual and the welfare of society (Talous, 2012).

Educational objectives are referred to as the most starting point in planning a successful educational work, both in the near and long term. And help to evaluate the educational process and education. Also, refer to the type of activities required to achieve successful learning. And represent appropriate criteria for selecting the best teaching methods in the fields of education (Stoyanova \& Yovkov, 2016).

Educational objectives must have some intrinsic characteristics:

1) Educational goals must be in accordance with the human nature, taking into account their needs and the possibility of launching their creative capacities.

2) To achieve the objectives of the relationship between the individual and society, and then between him and the social heritage of beliefs, values, traditions and problems.

3) That these objectives meet the needs of the present society and solve problems.

4) Educational goals must be flexible and changeable as required by ongoing development and renewable knowledge.

5) The objectives of educational goals should guide workers to what they should learn, and help them to identify the necessary methods in education, and tools to measure the results of the educational process and evaluation. 
6) The educational goals should clarify the type of knowledge, skills, attitudes, and habits which are intended to develop in the personality of the learner.

7) The educational goals should be comprehensive in the light of the relationships that determine the origin of man, his destiny and his relations with the universe, man and life around him (Stoyanova \& Yovkov, 2016).

8) Possibility to practice and apply the reasons for achieving these educational goals.

9) To be realistic: When we say realistic means emphasis goals are achievable under normal school. If our purpose was to achieve these goals in our schools, we must be satisfied with the reality in which our schools live in order to improve the conditions of schools.

10) Educational goals must be specific to desired behavior and can be recorded and measured.

11) To achieve the educational goals it must link results and behavior, what the individual practices must be linked to the results.

12) Educational goals must be free of contradictions (Kalnins, 2013).

The importance of the educational goals in the educational process is highlighted as follows:

1) The educational goals of a society are concerned with the formulation of its beliefs, values, heritage, hopes, needs and problems.

2) The educational goals help the curriculum planners to select the educational content of the different stages of study and to formulate their important educational objectives.

3) Educational goals help to coordinate, organize and direct the work to achieve the great goals and to build human integrated mental, skilled and emotional in different areas.

4) Educational goals play a prominent role in the development of educational policy and guiding the educational work of any society.

5) Educational goals help to define the good implementation of the curriculum in terms of the organization of teaching methods, and the organization and design of various methods of evaluation (AL-Mudakhili, 2014).

The educational goals must have basic elements in the behavioral purpose: the final behavior is the element of behavior desired to be generated by the learner; the content of the educational material, conditions and circumstances in which the learner achieves the behavior to be achieved; performance criteria through minimum performance (Pappas, 2015).

Bloom's Taxonomy is one of the most popular classifications of educational goals. This classification includes six levels:

1) Knowledge related to cognitive processes.

2) Understanding which is linked to its objectives by interpretation and conclusion;

3) Application includes abstract symbols.

4) Analysis includes the dismantling of the whole into its basic elements with the sequence of ideas;

5) Synthesis includes the arrangement of elements and the integration of parts in such a way as to create a new plan or structure that the learner has never seen.

6) Evaluation: Judging the value of tools and methods used to achieve the goal (Sajjadi, Davoudi, Saberi, Sanaeinasab \& Mehrabi, 2016).

Bloom's Taxonomy of educational goals is divided into three sections:

1) Cognitive domain: related to remembering knowledge, abilities and mental skills, it includes six levels of comprehension, understanding, applying, analyzing, synthesizing, and evaluating.

2) Psychological domain: is the field of skill related to the physical aspects of kinetics associated with the cognitive and emotional characteristics.

3) Emotional domain: an area that contains goals in interests, trends, tendencies, values and estimates (Reni, 2012).

Scientists have worked hard to classify them as educational goals that may be relevant to the field, the emotional field, and the psychological field, after they have worked to divide these areas to varying levels of difficulty, yet they are interrelated, so that the subsequent can be understood only after the recognition of the former. Bloom's Taxonomy of the cognitive or mental domain appeared and Krathol's classification of emotional field and the 
Simpson classification of the psychodynamic field or motor performance (Hwang, Chen, \& Huang, 2016).

However, the disadvantages of using educational goals lie not in themselves, but in the use of teachers. There are many studies that have shown an advantage in the use of educational goals, and proved the effectiveness of providing students with these goals in their academic achievement compared to those who did not provide them (Khalifa, 2014; Al-Ghamdi, 2012; Jack \& Marry, 2016).

The educational goals remained a controversial topic for teachers, researchers, educators, and among the aspects of this issue and the clarity of the gap between what the teachers are trying to do and what they Educational objectives will continue to play a key role in planning and teaching (Sajjadi et al., 2016). However, many applied studies have indicated that most teachers do not use goals widely and systematically in the educational process (AL-Modakhli, 2014). Khalifa (2014) noted that teachers do not tend to use or pay attention to goals.

\subsection{The Problem of the Study and Its Questions}

It was noted during the follow-up of students and teachers and the researcher's observation of the preparation of some teachers of the primary and secondary stages that many of them do not pay much attention to the emotional and psychological goals and most of their interest is focused on cognitive goals, as if other goals, especially emotional goals does not attract them, note that on all occasions education progress on instruction. It is well known that what is concerned with the development of values and trends are the emotional goals. Many educators have pointed to the weakness of learners in competencies of knowledge, skills, values and trends sought by the curricula at various levels and fields (Awada, 2016). Therefore, this study seeks to know the level of goals used by teachers in their planning notes by answering the following questions:

1) What is the reality of the use of teachers in the various stages at Amman Directorate of Education for the areas of teaching goals (cognitive, emotional, and psychological)?

2) Does the use of teachers in Amman Directorate of Education of the areas of teaching objectives (cognitive, emotional, and psychological) differ depending on years of teaching experience (6 years and less, more than 6 years)?

3) Does the use of teachers in Amman Directorate of Education of the areas of teaching objectives (cognitive, emotional, and psychological) differ depending on the stage in which they are teaching (lower basic stage, upper basic stage, secondary stage)?

4) Does the use of teachers in Amman Directorate of Education of the areas of teaching objectives (cognitive, emotional, and psychological) differ depending on the stage in which they are teaching (lower basic stage, upper basic stage, secondary stage?

5) Does the use of teachers in Amman Directorate of Education of the areas of teaching objectives (cognitive, emotional, and psychological) differ depending on gender (male, female)?

\subsection{Significance of the Study}

The importance of this study is to identify the inadequacies of teachers' abilities to develop educational goals that allow them to address this deficiency in order to improve their educational performance. It also seeks to identify the fact that teachers are aware of the three levels of goals (cognitive level, emotional level and psychological level) in their daily planning notes for the success of the learning process in achieving its goal. This helps to derive the teaching goals.

This study, in addition to available educational literature, provides a theoretical framework that helps to increase understanding of the nature of these variables (gender, service, educational stage), and provide the educational process in the Ministry of Education and the directorates with information related to the abilities of teachers in the formulation of educational goals.

\subsection{Objectives of the Study}

This study seeks to reveal the extent of realism that teachers use for the educational goals of the three levels in the prepared notebook in Amman Directorate of Education and the extent to which these objectives are affected by the following variables: service (Six years and less/more than six years), gender (male teachers/female teachers), and educational stages (primary/secondary).

\subsection{Procedural Definition of Terms}

Educational goal: The change is expected to occur in the personality of the learner after passing through an intended learning experience so that this change is reflected on the behavior of the learner to ensure his observation and evaluation. 
Lesson plan: What the teacher prepares in the preparation book before entering the classroom, including the objectives of behavioral methods and methods, activities and evaluation and the proposed method of implementing the classroom in addition to the observations that may be needed by the educational situation.

Teaching stages in Jordan: Education in the Hashemite Kingdom of Jordan is divided into primary and secondary, the primary education period is ten years, six in the lower primary and four in the upper primary, and secondary education consists of grades 11 and 12 .

\subsection{Limitation of Study}

1) The current study was limited to the teachers in Amman Directorate of Education and did not include the rest of the teachers in the other directorates.

2) The current study was limited to teachers during the second semester of the academic year 2016-2017.

3) The results of the present study are determined in light of the used concepts and terminology.

4) The results of the present study are determined by the study instrument used and the extent of psychometric properties.

\section{Previous Studies}

Agha (2017) conducted a study aimed to analyze the content of the interpretation of Holly Quran for secondary school in light of the educational objectives assigned to it. The study sample consisted of (400) students in Khan Yunis. The results of the study showed that the existence of (9) goals including (148) function on those goals in the first semester of the eleventh grade. The results also indicated that there are (7) objectives that include (213) function on these objectives in the first semester of the twelfth grade.

Tííska and Čtrnáctová (2017) conducted a study aimed to verify educational objectives in chemistry education in the Czech Republic. The results indicated that active activities have a significant role in applying the highest level of Bloom's educational goals, so that students can achieve the goals of acquiring knowledge and skills at the lower levels.

Sajjadi et al. (2016) conducted a study aimed to identify the extent to which trainees achieved educational goals during health training courses in Tehran. The study sample consisted of (56) students. The results of the study showed that $60 \%$ of students were able to acquire knowledge, new skills.

Hwang, Chen, and Huang's (2016) study examined the development of an individual education system based on Bloom's educational objectives classification. The study sample consisted of two experimental and control groups, each group 47 students. The results showed that the experimental group applied to the system indicated that the system helped students to learn more effectively and achieve success through the mechanism of personal enhancement and learning process in the light of the diagnostic table.

Cheng's (2016) study aimed to identify the relationship between teachers' ideological methods and their students' achievement of educational goals in Taiwan. The study sample consisted of (330) students. The results of the teachers showed a strong influence of the ideological methods of the teachers on the achievements of the students based on the educational goals. The study indicated that the teachers adopted ideological methods based on the existing situation.

Hamid's (2015) studied aimed to identify the position of the implementation of the objectives in the Islamic education materials at the basic stage, and the sample of the study consisted of (93) male and female teachers. The results of the study showed that there are no differences in the application of the objectives due to scientific specialization or years of experience.

Fernandez-Delgado, Mucientes, V'azquez-Barreiros, and Lama (2014) examined the goal of learning analysis that predicts achieving the learning objectives. The study sample consisted of (56) students. The results of the study showed that the adaptation of teachers with the design of learning is the most predictive of achieving the educational objectives in excess of $80 \%$ by focusing on educational resources and activities related to these goals.

The study of Al-Ghamdi (2012) aimed to identify the extent to which the educational objectives that topped the subjects of the literary texts assessed on middle school students were analyzed. (146) educational objectives were analyzed. The sample consisted of $50 \%$ teachers and $47 \%$ supervisors. The results showed that the percentage of educational objectives for the skills of literary criticism in the classes was as follows: First medium grade $29 \%$, second medium grade $47 \%$, third medium $50 \%$.

The Reni's (2012) study indicated the role of multiple intelligences in achieving educational goals across Bloom's levels. The study sample consisted of 736 students. The results of the study showed that multiple intelligences had 
a positive impact on learning and achievement of educational goals. There was a significant impact on the handling of curricula to achieve educational goals, and there was no gender impact on the achievement of educational goals.

\section{Method and Procedures}

\subsection{Study Approach}

The study followed the analytical descriptive method using the method of content analysis in quantitative analysis, where the last two plans were analyzed for 126 teachers. Thus, the number of school plans analyzed 252 study plans, in order to investigate the real use of Arabic language teachers in the different stages of education in Amman Directorate of Education for the fields of teaching objectives (knowledge, emotional, psychological).

\subsection{The Study Population}

The study population is composed of all teachers in Amman Directorate of Education for the academic year (2016-2017), The total number of teachers (2498) males and (1538) female teachers distributed in 50 schools for males and (94) for girls.

\subsection{The Study Sample}

The sample of the study consisted of 126 individuals 62 males teachers and 64 female teachers. They were selected by the mean method through twenty schools, ten male teachers and ten female teachers. Table 1 shows this.

Table 1. Members of the study sample and behavioral goals for each stage of the study

\begin{tabular}{|c|c|c|c|c|c|c|c|c|c|c|c|}
\hline \multicolumn{4}{|c|}{ Lower basic stage } & \multicolumn{4}{|c|}{ Higher basic stage } & \multicolumn{4}{|c|}{ Secondary stage } \\
\hline \multicolumn{2}{|c|}{ Male } & \multicolumn{2}{|c|}{ Female } & \multicolumn{2}{|c|}{ Male } & \multicolumn{2}{|c|}{ Female } & \multicolumn{2}{|c|}{ Male } & \multicolumn{2}{|c|}{ Female } \\
\hline $\begin{array}{l}6 \text { years } \\
\text { and less }\end{array}$ & $\begin{array}{l}\text { More } \\
\text { than } 6 \\
\text { years }\end{array}$ & $\begin{array}{l}6 \text { years } \\
\text { and less }\end{array}$ & $\begin{array}{c}\text { More } \\
\text { than } 6 \\
\text { years }\end{array}$ & $\begin{array}{l}6 \text { years } \\
\text { and less }\end{array}$ & $\begin{array}{l}\text { More } \\
\text { than } 6 \\
\text { years }\end{array}$ & $\begin{array}{l}6 \text { years } \\
\text { and less }\end{array}$ & $\begin{array}{l}\text { More } \\
\text { than } 6 \\
\text { years }\end{array}$ & $\begin{array}{l}6 \text { years } \\
\text { and less }\end{array}$ & $\begin{array}{l}\text { More } \\
\text { than } 6 \\
\text { years }\end{array}$ & $\begin{array}{l}6 \text { years } \\
\text { and less }\end{array}$ & $\begin{array}{l}\text { More } \\
\text { than } 6 \\
\text { years }\end{array}$ \\
\hline 6 & 8 & 10 & 8 & 9 & 13 & 6 & 16 & 8 & 18 & 12 & 12 \\
\hline \multicolumn{2}{|c|}{14} & \multicolumn{2}{|c|}{18} & \multicolumn{2}{|c|}{22} & \multicolumn{2}{|c|}{22} & \multicolumn{2}{|c|}{26} & \multicolumn{2}{|c|}{24} \\
\hline \multicolumn{2}{|c|}{72 goals } & \multicolumn{2}{|c|}{162 goals } & \multicolumn{2}{|c|}{156 goals } & \multicolumn{2}{|c|}{202 goals } & \multicolumn{2}{|c|}{284 goals } & \multicolumn{2}{|c|}{254 goals } \\
\hline
\end{tabular}

\subsection{Study Tool}

The researcher prepared a form to analyze the educational goals of the male and female teachers' lesson plans. Where it was divided into three domains: cognitive, emotional, and psychological. The researcher relied on Bloom's taxonomy of cognitive goals in its six levels: (knowledge, comprehension, application, analysis, synthesis, and evaluation). Krathwol's taxonomy of emotional goals was also divided into five levels: reception, response, value giving, organization, integration. He relied on the Simpson taxonomy of goals, the psychological domain is divided into seven levels: perception, configuration, directed response, mechanism, complex adaptation, innovation, creativity.

a list of the actions used in the formulation of the educational objectives was prepared, including the three domains (cognitive, emotional, psychological and kinetic) and its different levels, by reviewing the literature of scientific education, which addressed the educational objectives to use in the analysis. The possibility of certain actions being existed at more than one level of the three levels at the same time has been taken into account, in which case the scope of the objective was derived of the general formulation of the item.

\subsection{Validity and Reliability of the Tool}

In this research, content validity was adopted, the questionnaire was presented in a preliminary form to a group of faculty members specialized in the field of curriculum and teaching methods, tests and scales, then the observations were taken in terms of the relevance of some items to their themes or language, they agreed that the analysis tool was appropriate for the intended measurement of the study, indicating the arbitrators' validity of the instrument. To verify the reliability of the analysis tool used, the analysis was repeated again on a sample of behavioral objectives (757) objectives in (97) study plans, after three weeks to calculate the reliability coefficient according to the following equation:

$$
\text { Agreement percentage }=\frac{\text { Number of times agreed }}{\text { Number of times of agreement }+ \text { number of times of disagreement }} \times 100
$$

The general reliability coefficient of the questionnaire (0.91) was considered to be high and acceptable for the 
purposes of this study.

\subsection{Study Procedures}

1) Ten primary schools were selected from the first grade up to the twelfth grade, five female schools with (641) teachers, five male schools with (612) teachers.

2) The last two plans of each teacher were selected from the books of their preparation. The number of plans taken from the males reached 124 study plans, of which 28 were for the basic stage, with 72 were goals, and $\mathrm{t}(44)$ plans for upper basic stage with a number of goals reached 156, and 52 plans for secondary stage, the objectives reached 284 goals, and the number of plans taken for the females (128) plans, of which 36 study plans for the lower basic stage. the number of goals reached 162 goals, 44 study plans for higher basic stage, the number of goals reached 202 behavioral goals, 48 study plans with 254 behavioral goals.

\subsection{Statistical Treatment}

In order to answer the study questions, the average number of behavioral goals, the percentage of frequency of each domain of the three educational objectives, and for each of the different stages, as well as the gender variable, when comparing the effect of gender and different stages on the frequency of percentage of goals, the researcher used Chi-square $\left(\chi^{2}\right)$ to show the significance of the differences. The study included the following variables:

1) Gender: It has two categories (male teacher, female teacher).

2) Length of service: It has two categories (6 years and less, more than 6 years).

3) Educational stage: It has three categories (lower basic stage, higher basic stage, secondary stage).

4) Educational goals: It includes three dimensions (cognitive, emotional, and psychological).

\section{Results of the Study}

Below are the results for each of the questions that the study attempted to answer.

The first question: What is the reality of the use of Arabic language teachers in the different stages of education in Amman Directorate of Education for the domains of teaching objectives (cognitive, emotional, and psychological)?

To answer this question, the frequency and percentage of behavioral goals were used according to the educational stage, according to the gender of the teacher. Table 2 indicates these results.

Table 2. Frequency and percentages of educational objectives according to its domain, educational stage and gender of teacher

\begin{tabular}{|c|c|c|c|c|c|c|c|c|}
\hline \multirow[b]{2}{*}{ Domain } & \multirow[t]{2}{*}{ Stage } & \multicolumn{2}{|c|}{ Lower basic stage } & \multicolumn{2}{|c|}{ Higher basic stage } & \multicolumn{2}{|c|}{ Secondary } & \multirow{2}{*}{ Total } \\
\hline & & Male & Female & Male & Female & Male & Female & \\
\hline \multirow{2}{*}{ Cognitive } & Frequency & 40 & 102 & 98 & 142 & 200 & 211 & 793 \\
\hline & Percentage & $3 \%$ & $9 \%$ & $8 \%$ & $13 \%$ & $18 \%$ & $19 \%$ & $70 \%$ \\
\hline \multirow{2}{*}{ Psychological } & Frequency & 23 & 45 & 36 & 40 & 60 & 32 & 236 \\
\hline & Percentage & $2 \%$ & $4 \%$ & $3 \%$ & $4 \%$ & $5 \%$ & $3 \%$ & $21 \%$ \\
\hline \multirow{2}{*}{ Emotional } & Frequency & 9 & 15 & 22 & 20 & 24 & 11 & 101 \\
\hline & Percentage & $1 \%$ & $1 \%$ & $3 \%$ & $1 \%$ & $2 \%$ & $1 \%$ & $9 \%$ \\
\hline \multirow{4}{*}{ Total } & Frequency & 72 & 162 & 156 & 202 & 284 & 254 & 1130 \\
\hline & Percentage & $6 \%$ & $14 \%$ & $14 \%$ & $18 \%$ & $25 \%$ & $23 \%$ & \\
\hline & Frequency & \multicolumn{2}{|c|}{234} & \multicolumn{2}{|c|}{358} & \multicolumn{2}{|c|}{538} & $00 \%$ \\
\hline & Percentage & \multicolumn{2}{|c|}{$20 \%$} & \multicolumn{2}{|c|}{$32 \%$} & \multicolumn{2}{|c|}{$48 \%$} & $100 \%$ \\
\hline
\end{tabular}

Table 2 shows that the secondary stage was the most educational stage that use the educational goals, where the percentage of use at that stage was $48 \%$ divided into $25 \%$ and $23 \%$ for male and female teachers respectively, i.e., the use of male teachers for behavioral goals at that stage more than the use of female teachers, and the higher basic stage came in the second rank, where the percentage of use of educational objectives, regardless of the field to which they belong form $32 \%$, was divided into two percentages: $14 \%, 18 \%$ for male and female teachers respectively, in other words, the percentage of female teachers using the educational goals in the higher basic stage is greater than that of male teachers. then the lower basic stage occupied the third rank, where the percentage of use at that stage, regardless of its domains was $20 \%$ divided into two percentages of use $6 \%$ for male teachers, and $14 \%$ 
for female teachers, that is, the percentage of female teachers using the educational goals in the lower basic stage is greater than that of male teachers.

Table 2 also shows that the percentage of educational goals from the cognitive domain ranked first with $70 \%$, of which $12 \%$ were in the lower basic stage, $21 \%$ in the higher basic stage, $37 \%$ in the secondary stage, and the educational psychology objectives came in the second rank where it reached $21 \%, 6 \%$ in the lower basic stage, $7 \%$ in the upper basic stage, $8 \%$ in the secondary stage, then came the educational objectives in the third rank where its percentage reached $9 \%, 2 \%$ of them in the lower basic stage, $4 \%$ in the upper basic stage, and $3 \%$ in the secondary stage.

After presenting the findings on the reality of the use of teachers in the various stages of education for the domains of behavioral goals by educational stage and gender of the teacher, the following conclusions can be reached:

1) Teacher use of educational goals is increasing as the level of education they teach increases.

2) The most behavioral goals used in different stages of education are the cognitive goals, followed by the psychological, and the least used are the emotional.

3) Female teachers are more commonly using the behavioral objectives than male teachers in the lower and upper basic education stages, while male teachers were more frequently using it than female teachers in the secondary stage.

To identify the reality of the use of teachers in the different stages at Amman Directorate of education for the educational objectives' domains (cognitive, emotional, psychological), depending on the stage and years of experience, repetition of educational goals and percentages by educational stage were used as shown in Table 3 .

Table 3. Frequency and percentage of educational objectives by educational stage and years of experience

\begin{tabular}{|c|c|c|c|c|c|c|c|c|}
\hline \multirow[b]{2}{*}{ Domain } & \multirow{2}{*}{ Stage } & \multicolumn{2}{|c|}{ Lower basic stage } & \multicolumn{2}{|c|}{ Higher basic stage } & \multicolumn{2}{|c|}{ Secondary } & \multirow[b]{2}{*}{ Total } \\
\hline & & $\begin{array}{c}6 \text { years and } \\
\text { less } \\
\end{array}$ & $\begin{array}{c}\text { More than } 6 \\
\text { years }\end{array}$ & $\begin{array}{c}6 \text { years and } \\
\text { less }\end{array}$ & $\begin{array}{c}\text { More than } 6 \\
\text { years }\end{array}$ & $\begin{array}{c}6 \text { years and } \\
\text { less } \\
\end{array}$ & $\begin{array}{c}\text { More than } 6 \\
\text { years }\end{array}$ & \\
\hline \multirow{2}{*}{ Cognitive } & Repetition & 50 & 92 & 102 & 138 & 183 & 228 & 793 \\
\hline & Percentage & $4.5 \%$ & $8.2 \%$ & $9 \%$ & $12.1 \%$ & $16.1 \%$ & $20.1 \%$ & $70 \%$ \\
\hline \multirow{2}{*}{ Psychological } & Repetition & 25 & 43 & 31 & 45 & 37 & 55 & 236 \\
\hline & Percentage & $2.2 \%$ & $3.8 \%$ & $\% 2.7$ & $4 \%$ & $3.3 \%$ & $5 \%$ & $21 \%$ \\
\hline \multirow{2}{*}{ Emotional } & Repetition & 10 & 14 & 18 & 24 & 14 & 21 & 101 \\
\hline & Percentage & $0.9 \%$ & $1.2 \%$ & $1.6 \%$ & $2.2 \%$ & $1.2 \%$ & $1.9 \%$ & $9 \%$ \\
\hline \multirow{2}{*}{ Total } & Repetition & 85 & 149 & 151 & 207 & 234 & 304 & 1130 \\
\hline & Percentage & $7.5 \%$ & $13.2 \%$ & $13.4 \%$ & $18.3 \%$ & $20.7 \%$ & $26.9 \%$ & $100 \%$ \\
\hline
\end{tabular}

Table 3 shows that teachers with more than 6 years of experience were more used for teaching objectives than teachers of experience 6 years or less. The actual use of educational objectives of teachers with more than 6 years' experience was $58.4 \%$ regardless of the educational stage, the percentages were divided into: $13.2 \%, 18.3 \%$, $26.9 \%$ for lower basic stage, then higher then secondary, respectively, while the proportion of teachers with less than 6 years of experience was $41.6 \%$ regardless the educational stage which was divided into: $7.5 \%, 13.4 \%$, $20.7 \%$ for the lower basic stage, then higher then secondary, respectively. It is noted from Table 3 that the use of teachers with 6 years or less experience regardless of their domains was less than the use of teachers with more than 6 years' experience within the educational stage, and that the percentage of the use of teachers with experience 6 years or less for behavioral goals within the same domain was less than the use of teachers with more than 6 years of experience, whether within the educational stage, or regardless of the educational stage. From the previous we note that the increase in use is relatively related to the increase years of experience and at all educational stages.

Question Two: Does the teachers' use of educational goals' domains (cognitive, emotional, psychological) at Amman Directorate of Education differ at $(\alpha=0.05)$ according to the teaching experience (6 years and less, more than six years)?

In order to answer this question, Kay ${ }^{2}$ was used to test whether the use of teachers in Amman Directorate of Education for educational objectives was independent from their teaching experience or that there was a degree of correlation between them. Table 4 shows these results. 
Table 4. $\mathrm{Kay}^{2}(2 \times 3)$ results to test the relationship between teachers' use of the educational objectives' domains and years of teaching experience

\begin{tabular}{|c|c|c|c|}
\hline Domain & 6 years and less & More than 6 years & Total \\
\hline \multicolumn{4}{|l|}{ Cognitive } \\
\hline Observed repetition & 335 & 458 & 793 \\
\hline Expected repetition & $(329.8)$ & $(463.2)$ & \\
\hline \multicolumn{4}{|l|}{ Psychological } \\
\hline Observed repetition & 93 & 143 & 236 \\
\hline Expected repetition & $(98.2)$ & (137.8) & \\
\hline \multicolumn{4}{|l|}{ Emotional } \\
\hline Observed repetition & 42 & 59 & 101 \\
\hline Expected repetition & $(42.01)$ & $(58.99)$ & \\
\hline Total & 470 & 660 & 1130 \\
\hline \multicolumn{4}{|l|}{$\mathrm{Kay}^{2}=0.622$} \\
\hline $\mathrm{Kay}^{2}$ critical level 0.05 , degrees of fr & $\mathrm{om} 2=5.99$ & & \\
\hline
\end{tabular}

Table 4 shows that the variables of teachers' usage for the teaching objectives' domains and the years of teaching experience are independent from each other. In other words, there is no relationship between teachers' use of the domains of teaching objectives (cognitive, psychological, and emotional) and years of experience (6 years and less, more than 6 years). The value of $\mathrm{kay}^{2}$ was calculated 0.622 , which is much lower than the probability value of $\mathrm{kay}^{2}$ which is 5.99 at the significance level $(0.05)$ and the degrees of freedom (2). When calculating the correlation coefficient, its value was 0.02 which indicates the weakness of the relation between the reality of teachers' use of the domains of teaching objectives and their years of teaching experience noting that the maximum probability of compatibility is estimated at 0.58 .

The third question: Does the use of educational objectives by the teachers at Amman Directorate of Education differ at $(\alpha=0.05)$ according to the stage they are teaching?

To answer this question, $\mathrm{Kay}^{2}$ was used to test whether teachers' use of the domains of teaching objectives was independent from the type of educational stage they are teaching at, or whether there was a degree of relationship between them. Table 5 shows the results of this test.

Table $5 . \mathrm{Kay}^{2}$ results $(3 \times 3)$ to test the relationship between teachers' use of the educational objectives' domains and the type of stage they are teaching

\begin{tabular}{|c|c|c|c|c|}
\hline Domain $\quad$ Educational stage & Lower basic stage & Higher basic stage & Secondary & Total for observer \\
\hline \multicolumn{5}{|l|}{ Cognitive } \\
\hline Observed repetition & 142 & 240 & 411 & \multirow{2}{*}{793} \\
\hline Expected repetition & $(164.2)$ & $(251.2)$ & $(377.6)$ & \\
\hline \multicolumn{5}{|l|}{ Psychological } \\
\hline Observed repetition & 68 & 76 & 92 & \multirow{2}{*}{236} \\
\hline Expected repetition & $(48.9)$ & $(74.8)$ & $(112.4)$ & \\
\hline \multicolumn{5}{|l|}{ Emotional } \\
\hline Observed repetition & 24 & 42 & 35 & \multirow{2}{*}{101} \\
\hline Expected repetition & $(20.92)$ & $(31.998)$ & $(48.09)$ & \\
\hline Total for observer & 234 & 358 & 538 & 1130 \\
\hline \multicolumn{5}{|l|}{$\mathrm{Kay}^{2}=(081,24)$} \\
\hline $\mathrm{Kay}^{2}$ critical at the level of $(0.05)$ an & legrees of freedom & $=9.49$ & & \\
\hline
\end{tabular}

Table 5 shows a relationship between teachers' use of the educational objectives' domains and the stage they are teaching at. Critical value Kay ${ }^{2}$ was 9.49 at the level of statistical significance (0.05) and degrees of freedom (4). This means that the variables of the educational stage and the use of teachers for the objectives' domains are not independent. When calculating the correlation coefficient, it was found that its value $(0.15)$ indicates that there is a relationship that is not high despite its existence and its statistical significance, compared with the maximum limit 
of the correlation coefficient which reached 0.67 .

Question Four: Does the use of teachers at Amman Directorate of Education of the objectives' domains (knowledge, emotional, psychological), differ at (0.05) according to their gender (Male, Female)?

To answer this question, $\mathrm{Kay}^{2}$ was used to test whether teacher use of the educational objectives' domains was independent of their gender, or that there was a degree of correlation between them, and Table 6 shows the results.

Table 6. Results of $\mathrm{Kay}^{2}(2 \times 3)$ to test the relationship between teachers' use of the areas of teaching objectives and their gender

\begin{tabular}{|c|c|c|c|}
\hline Domain & Males & Females & Total for observer \\
\hline \multicolumn{4}{|l|}{ Cognitive } \\
\hline Observed repetition & 338 & 455 & 793 \\
\hline Expected repetition & $(359.31)$ & $(433.7)$ & \\
\hline Psychological & & 1 & \\
\hline Observed repetition & 119 & 17 & 236 \\
\hline Expected repetition & $(106.931)$ & $(129.07)$ & \\
\hline \multicolumn{4}{|l|}{ Emotional } \\
\hline Observed repetition & 55 & 46 & 101 \\
\hline Expected repetition & $(45.763)$ & $(55.24)$ & \\
\hline Total for observer & 512 & 618 & 1130 \\
\hline \multicolumn{4}{|l|}{$\mathrm{Kay}^{2}=254,8$} \\
\hline \multicolumn{4}{|c|}{$\mathrm{Kay}^{2}$ critical at the level $(0.05)$ and degrees of freedom $(2)=(5.99)$} \\
\hline
\end{tabular}

Table 6 shows that there is a statistically significant relationship between the teachers' use of the domains of educational objectives and their gender. The value of $\mathrm{Kay}^{2}$ is 8,254 , which is greater than the value of critical Kay ${ }^{2}$ (5.99) at the statistical significance level 0.05 and the degrees of freedom (2).

This means that the variables used by the teachers for the domains of educational objectives and gender are not independent. When calculating the correlation coefficient, it was found to be 0.09 , while the upper limit of the correlation coefficient was 0.58 , which means that the correlation between the gender of the teacher and the use of the teaching objectives is not high, considering that relationship, although its statistical significance is weak.

\subsection{Discussion of the Results}

The first question may be attributed to the ease of formulating educational objectives in field of knowledge because they form them, but if they compared with the psychological and cognitive educational goals in terms of difficulty in order. Sa'ada (2013) mentioned that teachers fail to formulate cognitive goals because they set cognitive goals across their different stages of education. They also difficult to measure and observe, and they need a longer period of time to be achieved when compared to the goals of psychology and knowledge.

As for the result of the high percentage of educational goals in the daily preparation plans for teachers according to the stage, this can be explained, among other things: like the higher-level of teachers may be more experienced or achieving educational goals for young people may take more time than adults, because of the need for more activities to achieve the educational goal whenever the level of education is lower. It was noted that the most influential factors in the planning of the lessons are the experience of teachers and the school curriculum and the needs of the classroom environment in addition to the lack of time and resources and the lack of support from the school administration and educational supervisors.

With regard to the second question, this may be because more experienced teachers are more educationally qualified, as the Ministry of Education sends teachers in study missions to Jordanian universities to qualify them for a practical qualification in the Diploma and Master of Education programs and from the selection criteria for qualification years of teacher experience, and the teachers with the highest experience are the most fortunate in qualifying them in a methodical manner. The results of this study differ from Hamed's (2015) study, which indicated no differences due to years of experience.

The third question can be explained by this finding that teachers do not distinguish between the areas of teaching objectives that teachers focus on teaching content and not on the goals and this means the lack of awareness of the importance of teaching objectives for learners, and that the learners' awareness of what they should do after 
completion of teaching works to raise their motivation and thus increase their scientific achievement which led to a weak relationship between the use of teachers for the areas of behavioral goals and years of experience. This link can be seen if teachers really believe in the importance of instructional goals in the learning process, and that their use of target areas can be associated more with years of experience.

This finding can be attributed to the fact that the higher the level of education, the greater the need to increase teaching objectives, especially for the cognitive and psychological fields. This is observed through the repetition of those goals, whether observed or expected, which increase with the high level of the educational stage. If the relationship is not high between teachers' use of the areas of educational objectives and the type of educational stage they study, it may be due to the different need for the cognitive objectives emerged more need at upper elementary education stage. This non-high relationship may be attributed to the fact that teachers' use of the areas of teaching objectives in the upper primary stage was more than the primary and secondary stages.

As for the fourth question, this result can be explained by the equal outlook of teachers on the importance of diversity in the areas of teaching objectives. If this relationship is found to be weak, it may be because teachers are more likely to use teaching objectives, especially in the cognitive field. The result of this study is consistent with Chen's (Cheng, 2016) study, which noted that there is a strong influence of the methods of ideological teachers on student achievements based on educational goals.

\section{Recommendations}

In light of the findings of this study, the researcher recommends the following:

1) Prepare a manual that includes with representation how to derive the educational objectives of the curriculum at three levels, especially psychological goals and emotional goals.

2) Conducting studies on the extent to which educational objectives are represented by their three levels on the rest of the subjects.

3) Holding educational courses at high levels for teachers and educational supervisors to enable them to acquire the necessary skills to convert vocabulary, ideas, and educational products to educational goals.

\section{References}

Abdulkader, I. (2015). Behavioral objectives. Alexandria: University Education House.

Abu Arish, W. (2016). Behavioral goals in the educational process. Amman: House of Counselors for Publishing and Distribution.

Aga, H. (2017). Analysis of the content of the interpretation of the Koran to the secondary level in light of the educational objectives and the extent of student's acquisition of it (Unpublished Master Thesis, Islamic University, Gaza).

Al-Ghamdi, S. (2012). Analysis of the educational objectives of the subjects of literary texts on the students of the intermediate stage in Saudi Arabia in light of the skills of literary taste and criticism necessary for their students (Unpublished doctoral thesis, Omdurman Islamic University, Omdurman, Sudan).

Awadah, H. (2016). Educational goals. Beirut: Islamic Cultural Knowledge Society.

Cheng, Y. (2016). An investigation into the relationship between tutors' ideological styles and their students' learning achievements of educational objectives: An empirical study of digital media design education in Taiwan. An International Journal for All Aspects of Design, 19(5), 699-723. https://doi.org/10.1080/14606925.2016.1206702

Fernandez-Delgado, M., Mucientes, M., Vazquez-Barreiros, B., \& Lama, M. (2014). Learning analytics for the prediction of the educational objectives achievement. Paper presented at the Frontiers in Education Conference, Madrid, 22-25 Oct. 2014. https://doi.org/10.1109/FIE.2014.7044402

Hamid, N. (2015). The position of applying the emotional goals in Islamic education materials at the basic stage: an applied study on the state of Khartoum. Educational Studies, 4, 121-164.

Hwang, G., Chen, B., \& Huang, C. (2016). Development and Effectiveness Analysis of a Personalized Ubiquitous Multi- Device Certification Tutoring System Based on Bloom's Taxonomy of Educational Objectives. Educational Technology \& Society, 19(1), 223-236.

Jack, M., \& Marry, K. (2016). Content Analysis Basics In educational studies (6th ed.). New Jersey: University Press.

Kalnins, J. (2013). Long Term Goal Setting. New York: Amazon. 
Khalifa, A. (2014). Objectives and competencies: A comparative study of the concept of objectives and competencies in the educational process. Thought and Creativity, 85, 375-404.

Mudakhili, M. (2014). Content Analysis Methodology: Applications to Research Methods. Jeddah: Publications of Teachers College, King Abdul-Aziz University.

Pappas, C. (2015). Writing learning objectives for eLearning: What eLearning professionals should know. Retrieved from https://elearningindustry.com/writing-learning-objectives-for-elearning-what-elearningprofessionals-should-know

Reni, F. (2012). Multiple intelligence approach to curriculum transaction in achieving the educational objectives at secondary school level. ERIC: ED574184.

Saadeh, J. (2013). Using educational objectives in all subjects. Cairo: Dar Al-Zahraa for Publishing and Distribution.

Sabari, A. (2012). Evaluation of the Arabic Language Curriculum in Achieving Educational Goals: A Case Study of the Government University Malang, Indonesia (Unpublished $\mathrm{PhD}$ dissertation, Omdurman Islamic University, Omdurman).

Sajjadi, F., Davoudi, M., Saberi, I., Sanaeinasab, H., \& Mehrabi, T. (2016). Level of educational objectives achievement in health and community medicine internship course; Interns viewpoint. Bimonthly of Education Strategies in Medical Sciences, 9(1), 29-34.

Stoyanova, S., \& Yovkov, L. (2016). Educational objectives in E-learning. International Journal of Humanities Social Sciences and Education, 3(9), 8-11.

Taei, H. (2012). Educational goals and their applications in the Holy Quran and Sunnah. Baghdad: Center for Research and Islamic Studies.

Tř́ska, J., \& Čtrnáctová, H. (2017). The verification of educational objectives in the chemistry education of the Czech Republic. SHS Web Conf, 37(01073), 1-7. https://doi.org/10.1051/shsconf/20173701073

Tuls, M. (2012). Education in Islam. Cairo: Hindawi Foundation for Education and Culture.

Walid, M. (2014). Goal definition. Retrieved from http://mawdoo3.com

\section{Copyrights}

Copyright for this article is retained by the author(s), with first publication rights granted to the journal.

This is an open-access article distributed under the terms and conditions of the Creative Commons Attribution license (http://creativecommons.org/licenses/by/4.0/). 